\title{
Geo(Im)pulse
}

\section{River Meuse suspended sediment yield: a new estimate and past estimates revisited}

\section{P.J. Ward}

Department of Palaeoclimatology and Geomorphology, Faculty of Earth and Life Sciences, Vrije Universiteit Amsterdam, De Boelelaan 1085 , 1081 HV Amsterdam, the Netherlands. Email: philip.ward@falw.vu.nl

Manuscript received: December 2007; accepted: May 2008

\begin{abstract}
Despite increasing research into changes in the discharge of the River Meuse, estimates of the river's sediment yield are less forthcoming. Three published studies (in 1883, 1982, and 1987) have estimated suspended sediment yield at the Belgian-Dutch border; the latter two studies surmise that this increased substantially between the late 19th and 20th Centuries. In this paper a more recent and longer time-series of observed discharge and suspended sediment data $(1995-2005)$ is used to estimate mean annual suspended sediment yield (ca. 386,000 Mg. $\mathrm{a}^{-1}$ ), and the results of the previous studies are revisited. New insights suggest that those studies do not in themselves provide evidence of increased sediment yield: the higher estimates in the late 20th Century could equally be due to interannual variability or methodological differences. Furthermore, there has been no significant increase in rainfall erosivity between the late 19th and 20th Centuries, and the effect of land use change over that time would have been to cause a decrease in suspended sediment yield, rather than an increase.
\end{abstract}

Keywords: Meuse, sediment rating curves, sediment yield, soil erosion.

\section{Introduction}

Concerns surrounding the effects of anthropogenic climate and land use change have stimulated increasing research into River Meuse hydrology in recent years. Suspended sediment yield (SY) (the total mass of suspended sediment passing a specific location in a given time interval) is also sensitive to changes in climate and land use, but has received little attention, partly due to the lack of systematic measurements of suspended sediment concentration (SC). Nevertheless, an understanding of SY is essential as sediments from agricultural areas are responsible for the supply of nutrients, pesticides, and heavy metal contaminants to river channels (e.g. Boers, 1996; De Wit \& Behrendt, 1999), which can have an impact on the water quality of rivers and coastal areas. Furthermore, sediment delivery impacts on channel and floodplain morphology; the ecological functioning of floodplains (e.g. Richards et al., 2002); and sediment deposition rates in reservoirs and ponds (e.g. Verstraeten \& Poesen, 1999). Currently, the only estimates of SY at the scale of the Meuse basin are those of Spring \& Prost (1883), Close-Lecocq et al. (1982), and Lemin et al. (1987). The latter two studies suggest that a large increase in SY occurred between the late 19th and 20th Centuries. However, the estimates of SY in these studies are based on measurements made over short time-periods (maximum one year). Daily measurements of Meuse discharge (Q) and SC at Eijsden (the Netherlands) are now available for 1995 - 2005, thus providing a longer time-series. In this paper we use these observations to examine the following research questions:

- What is the recent mean annual SY of the Meuse at Eijsden?

- How does this estimate of SY compare to previous estimates?

- Has the SY of the Meuse increased since the late 19th Century, as postulated by Close-Lecocq et al. (1982) and Lemin et al. (1987)? 


\section{Previous studies of Meuse SY}

Spring \& Prost (1883) measured daily $Q$ and SC at Liège (Belgium) between November 1882 and November 1883. Daily SCs were estimated as the product of the instantaneous daily measurements of $Q$ and SC, integrated over the entire day (e.g. Phillips et al., 1999; Robertson \& Roerish, 1999), and were summed to estimate annual SY. Using this method they obtained an estimate of annual SY for that year of 238,191 Mg. Close-Lecocq et al. (1982) carried out a similar exercise one century later, taking measurements between December 1979 and April 1980, on a number of days in July 1980 (following a major high-flow), and between August 1980 and January 1981. Based on these measurements they developed the following rating curve:

$$
\log Q_{s}=1.9606 \cdot \log Q-0.73234 \quad(r=0.93)
$$

where $Q=$ discharge $\left(\mathrm{m}^{3} \mathrm{~s}^{-1}\right)$, and $Q_{\mathrm{S}}=$ suspended sediment flux $\left(\mathrm{g} \cdot \mathrm{s}^{-1}\right)$. Substitution of observed $Q$ data for Ampsin-Neuville (ca. $10 \mathrm{~km}$ upstream) for 1958 - 1977 into this regression model provided an estimate of mean annual SY of $388,458 \mathrm{Mg} \cdot \mathrm{a}^{-1}$. Based on this estimate they surmised that SY had increased significantly since the late 19th Century. Lemin et al. (1987) measured $Q$ and $S C$ at Liège on 62 days between January 1983 and February 1984, mainly during high-flows, and developed the following rating curve:

$$
\log Q s=2.14 \cdot \log Q-1.11 \quad(r=0.93)
$$

Using this regression equation with daily $Q$ data for 1983 , they calculated a SY for that year of $483,409 \mathrm{Mg} \pm 122,562 \mathrm{Mg}$, and state that this confirms the conclusion of Close-Lecocq et al. (1982), namely that Meuse SY increased strongly between the late 19th and 20th Centuries.

In a recent publication, Doomen et al. (2007) developed a supply-based rating curve for the estimation of Meuse SC for given values of $Q$. The rating curve is based on an empirically derived power function of the form:

$$
\mathrm{SC}=a Q^{b}+c
$$

where $a, b$, and $c$ are empirically derived coefficients. However, the rating curve differs from traditional power functions in that the coefficient $b$ varies depending on the presence or absence of sediment stock in the channel bed; when stock is present $b$ is higher (i.e. steeper rating curve), and when stock is exhausted $b$ is lower (i.e. less steep rating curve). Sediment stock is assumed to increase when discharge is below a given threshold, and decrease when discharge is above that threshold. This supply-based rating curve leads to an improvement in the prediction of SC when compared to rating curves which do not consider sediment depletion.

\section{Data and materials}

Data on daily $Q$ and SC for 1995 - 2005 at Eijsden were obtained from the Waterbase website (www.waterbase.nl). The measurements were taken continuously throughout the day, from which daily average values were obtained. In the present study, the mean daily values of $Q$ and SC were multiplied to estimate daily SY, and these daily estimates were summed to provide annual estimates. This method of estimating annual SY is considered to be the most accurate method if sufficient data (at least daily) are available (Robertson \& Roerish, 1999). Since these measurements are available daily, and are taken continuously throughout the day rather than once per day, it is assumed that they give a reasonably accurate estimate of SY, approaching the true value. Hence, in the present study I refer to these estimates as 'observed'. SC data were missing for 50 days, the days being spread throughout the year and the time period: for these days the concentration was estimated using the rating curve of Doomen et al. (2007).

\section{Results and discussion}

The mean annual observed SY for 1995-2005 at Eijsden, as calculated from daily observations of $Q$ and SC, is $386,000 \mathrm{Mg}$.; interannual variability is high ( $\sigma=231,000 \mathrm{Mg}$ ), as is the range (maximum $=725,000 \mathrm{Mg}$ and minimum $=73,000 \mathrm{Mg}$ ). The estimates of the three previous studies fall within the variability of these observed values. This immediately casts doubt on the conclusion of Close-Lecocq et al. (1982) and Lemin et al. (1987) that their results provide evidence of an increase in SY.

Furthermore, the different methodologies used in the previous three studies can themselves lead to large variations in estimates of SY. Close-Lecocq et al. (1982) and Lemin et al. (1987) used log linear sediment rating curves to estimate Qs as a function of $Q$. Such a log linear rating curve for 19952005 at Eijsden (Fig. 1) has the form:

$$
\log Q_{\mathrm{S}}=1.585463 \cdot \log Q-0.323742 \quad(\mathrm{r}=0.91)
$$

Despite the high correlation coefficient, Fig. 1 shows that the relationship is not truly log linear, since the gradient steepens at ca. $\log Q=2.5$. Since Close-Lecocq et al. (1982) and Lemin et al. (1987) used a limited numbers of observations biased towards high-flows, this change in gradient was not visible. For example, Lemin et al. (1987) based their rating curve on measurements of 62 days, and the minimum measurement of $Q$ on which their estimation was based is ca. $170 \mathrm{~m}^{3} \mathrm{~s}^{-1}$ (i.e. $\log Q=$ ca. $\left.2.23 \mathrm{~m}^{3} \mathrm{~s}^{-1}\right)$. Reference to Fig. 1 shows that a rating curve based on Eijsden observations only for days on which $\log Q>2.23$, would indeed be steeper.

To illustrate the sensitivity of log linear rating curves to the length of the measuring period used in their estimation, 


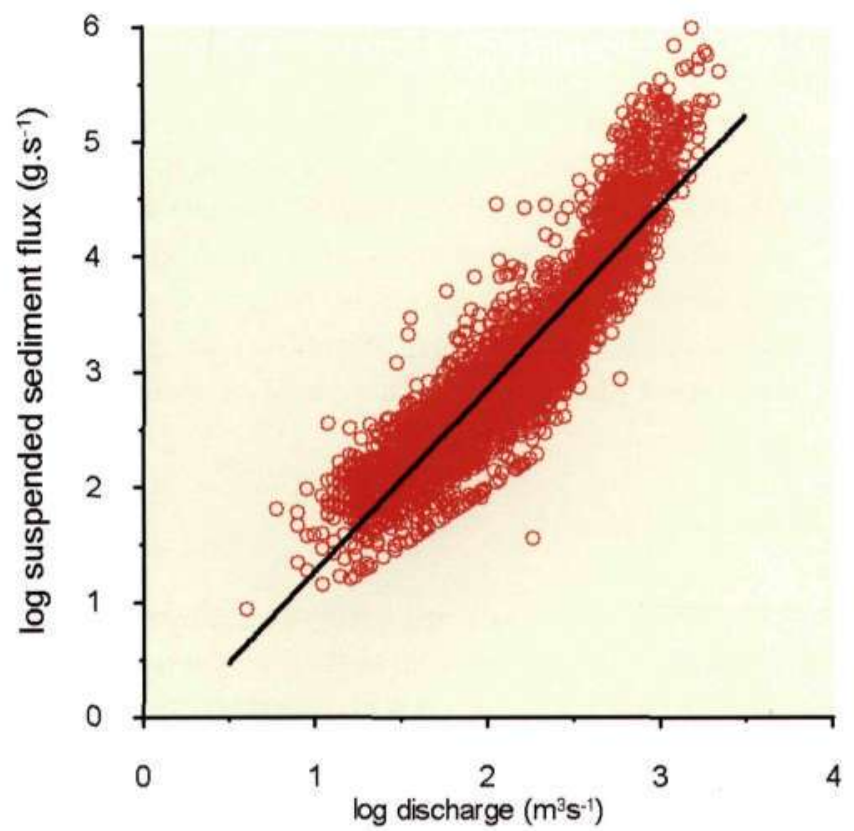

Fig, 1. Scatter plot of the logarithms of daily discharge and suspended sediment flux at Eijsden for 1995 - 2005. The black line indicates the log linear sediment rating curve between log discharge and log suspended sediment flux. Despite the high correlation coefficient $(r=0.91)$ the relationship is clearly not truly log linear; the gradient becomes more steep after log discharge $=c a .2 .5 \mathrm{~m}^{3} \mathrm{~s}^{-1}$.

$\log$ linear curves for each individual year of the Eijsden observations are plotted against the rating curve based on the entire period 1995 - 2005 (Fig. 2). For comparison purposes, the curves of Close-Lecocq et al. (1982) and Lemin et al. (1987) are also shown. The rating curves of the individual years at Eijsden show a large spread around the mean curve for 1995 2005; hence a rating curve based on an individual year of observations cannot be applied to $Q$ data of other years. Furthermore, Fig. 2 shows that the log linear rating curves of Close-Lecocq et al. (1982) and Lemin et al. (1987) are too steep since they are based on observations biased towards high-flows: the use of these curves will lead to an overestimation of SY.

\section{Predictive power of the regression curves}

When substituting observed $Q$ data into the individual annual log linear rating curves for Eijsden (Fig. 2), substantial underestimations of annual SY (compared to observed values for those years) were found in all cases (between $84.4 \%$ and $36.2 \%$ ). This discrepancy occurs for a large part because log linear regression curves are obtained based on least squares regression on the logarithms of $Q$ and $Q_{s}$. Hence, when the inverse logarithm is taken, the differences between observations and regression curve are greater for observations above the curve than for observations below the curve (Walling \& Webb, 1982; Ferguson, 1986; Asselman, 1997; Phillips et al., 1999). On the other hand, the rating curves of Close-Lecocq et

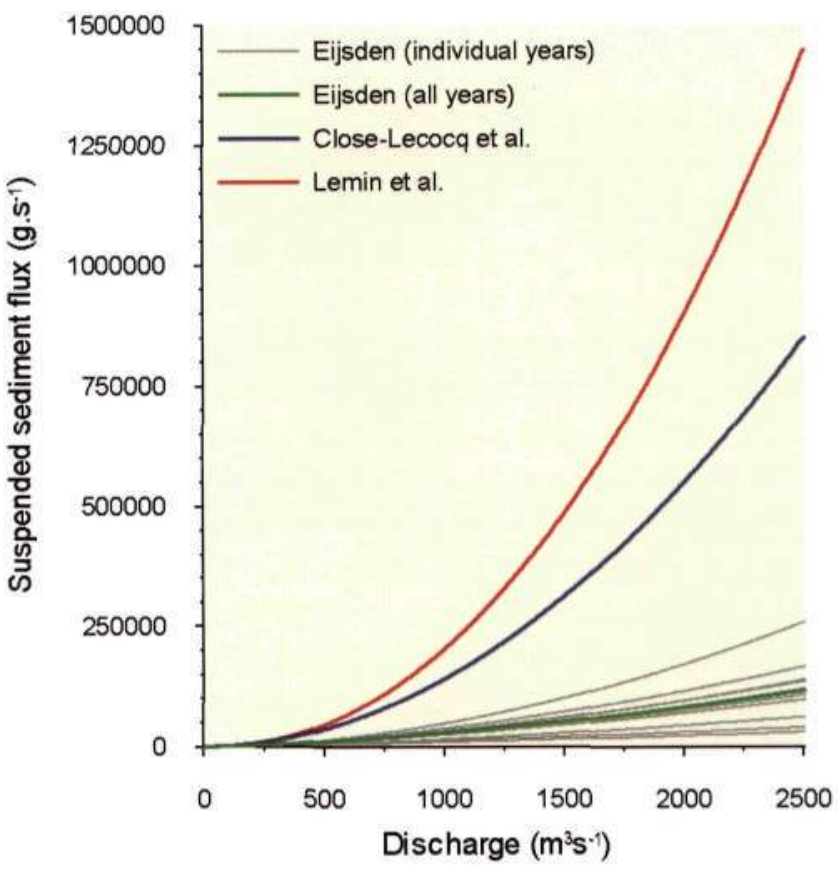

Fig. 2. Log linear sediment rating curves between discharge and suspended sediment flux. The curves based on individual years of observations at Eijsden (between 1995 and 2005) (grey) show a large spread around the curve based on observations for the all of the years in the period 1995 2005 taken together (green). Furthermore, all of these curves were found to produce an underestimation of annual $S Y$ of between $84.4 \%$ and $36.2 \%$. The curves of Close-Lecocq et al. (1982) and Lemin et al. (1987) are much steeper since they are based on discharge observations biased towards high-flows, and hence lead to an overestimation of SY.

al. (1982) and Lemin et al. (1987) both lead to a substantial overestimation of mean annual SY $(+83.0 \%$ and $+158.1 \%$ respectively). The use of these $Q$ observations biased towards high-flows to estimate sediment rating curves leads to severe overestimations of SY, despite the underestimation due to the use of log linear regression.

In order to assess the ability of the supply-based sediment rating curve of Doomen et al. (2007) to estimate annual SY, I used their method, in combination with the observed discharge data for Eijsden for 1995 - 2005, to estimate annual SY over that period. The agreement between observed annual SY, and SY estimated using this method, was reasonably good on a year to year basis ( $r=0.87$, Nash and Sutcliffe (1970) efficiency coefficient, $N \& S=0.71)$. The estimate of mean annual SY for the entire period (ca. $337,000 \mathrm{Mg} \cdot \mathrm{a}^{-1}$ ) was lower than that of the observed record (ca. $386,000 \mathrm{Mg} \cdot \mathrm{a}^{-1}$ ), although the difference is not statistically significant ( $\mathrm{t}$-test: $\mathrm{t}=0.512, \mathrm{p}=0.614$ ). Furthermore, the interannual variability of SY calculated using the method of Doomen et al. (2007) $(\sigma=211,000)$ is similar to that of the observed record (F-test: $F=0.900, p=0.354$ ). Hence this physically based rating curve, whilst actually developed for predicting daily SC, gives a better estimation of annual SY than the previously discussed SY rating curves. 


\section{Preliminary assessment of 20th Century SY changes}

On a long time-scale (i.e. centennial or longer), rating curves cannot be used to estimate SY as they are specific to the basin conditions during the period for which they are estimated. The most promising way to examine long-term changes would be through the use of models and proxy data. Whilst such a study is beyond the scope of this paper, the possible role that changes in climate and land use may have had on SY over the course of the last century are discussed briefly.

The most widely used parameter representing the erosional impact of rain on soils is the $\mathrm{R}$ factor of the Revised Universal Soil Loss Equation (RUSLE) (Renard et al., 1997). Verstraeten et al. (2006) made monthly estimates of the R factor at Ukkel (Belgium) for the period 1898-2002 based on observed 10-min rainfall depth time-series, and found neither a significant trend nor any abrupt changes in the 105 year time series. Hence, there was no significant increase in rainfall erosivity between the late 19th Century and the period in which the studies of Close-Lecocq et al. (1982) and Lemin et al. (1987) were carried out, and therefore no resultant significant increase in SY can be expected.

Land use is also an important factor controlling SY, with erosion in forests and urban areas generally very low, and erosion in agricultural areas higher. The percentage area of the Meuse basin (upstream from Eijsden) covered by forest was higher in the late 20th Century than in the late 19th Century (ca. $39 \%$ vs. $29 \%$ ), as was the percentage of urban area (ca. $9 \%$ vs. $2 \%$ ); the area of agriculture was lower in the late 20 th Century than in the late 19th Century (ca. $52 \%$ vs. $68 \%$ ) (Ward et al., 2008). Hence, the land use changes which have occurred between the late 19th and 20th Centuries would have the effect of reducing SY.

These findings lend support to the central notion of this study, namely that the higher values of SY obtained by CloseLecocq et al. (1982) and Lemin et al. (1987), compared to Spring \& Prost (1883), could just as well result from interannual differences in SY or differences in methodologies, rather than be indicative of a structural increase in mean SY.

\section{Conclusions}

- For the period 1995-2005, the mean annual estimated SY of the Meuse at Eijsden is approximately $386,000 \mathrm{Mg} \cdot \mathrm{a}^{-1}$. Interannual variability is high $(\sigma=231,000 \mathrm{Mg})$, as is the range of observed SY for individual years (between 73,000 and $725,000 \mathrm{Mg} \cdot \mathrm{a}^{-1}$ ).

- Sediment rating curves based on single year observations of $Q$ and SC are highly sensitive to the year used to calculate the regression model, and can lead to highly erroneous estimates of SY when applied to other years. When discharge data biased towards high-flows are used to estimate rating curves, large overestimations of SY can occur.
- The SY estimates of Spring \& Prost (1883), Close-Lecocq et al. (1982) and Lemin et al. (1987) fall within the range of observed annual values of Meuse SY at Eijsden from 1995 2005. Hence, it is not possible to conclude from the aforementioned studies that mean SY has increased since the late 19th Century. Furthermore, rainfall erosivity at Ukkel shows no significant trend between the late 19th and 20th Centuries, and changes in land use in that period would have led to a reduction in SY, rather than an increase.

\section{Acknowledgments}

This research project was carried out in the framework of the Dutch National Research Programme 'Climate changes Spatial Planning' (www.klimaatvoorruimte.nl). I would like to thank the two reviewers, Michel van der Meulen and Marcel van der Perk, as well as Gert Verstraeten, Ronald van Balen, Hans Renssen, Jef Vandenberghe, Jeroen Aerts, Siebolt Folkertsma, and Marcel de Wit for their valuable comments.

\section{References}

Asselman, N.E.M., 1997. Suspended sediment in the River Rhine. The impact of climate change on erosion, transport, and deposition. Ph.D. thesis. Universiteit Utrecht (Utrecht): $257 \mathrm{pp}$.

Boers, P.C.M., 1996. Nutrient emissions from agriculture in the Netherlands: causes and remedies. Water, Science and Technology 33: 183-189.

Close-Lecocq, J.F., Pissart, A. \& Koch, G., 1982. Les transports en suspension et en solution de la Meuse à Liege et à Tailfer (amont de Namur). Bulletin de la Société Géographique de Liège 18: 5-18.

De Wit, M.J.M. \& Behrendt, H., 1999. Nitrogen and Phosphorus emissions from soil to surface water in the Rhine and Elbe basins. Water Science Technology 39: 109-116.

Doomen, A.M.C., Wijma, E., Zwolsman, J.J.G. \& Middelkoop, H., 2007. Predicting suspended sediment concentrations in the Meuse River using a supply-based rating curve. Hydrological Processes, in press, doi:10.1002/hyp.6767.

Ferguson, R.I., 1986. River loads underestimated by rating curves. Water Resources Research 22: 74-76

Klein Tank, A.M.G., Wijngaard, J.B., Können, G.P., Böhm, R., Demarée, G., Gocheva, A., Mileta, M., Pashiardis, S., Hejkrlik, L., Kern-Hansen, C., Heino, R., Bessemoulin, P., Müller-Westermeier, G., Tzanakou, M., Szalai, S., Pálsdóttir, T., Fitzgerald, D., Rubin, S., Capaldo, M., Maugeri, M., Leitass, A., Bukantis, A., Aberfeld, R., Van Engelen, A.F.V., Forland, E., Mietus, M., Coelho, F., Mares, C., Razuvaev, V., Nieplova, E., Cegnar, T., Antonio López, J., Dahlström, B., Moberg, A., Kirchhofer, W., Ceylan, A., Pachaliuk, 0., Alexander, 0.V. \& Petrovic, P., 2002. Daily dataset of 20th-century surface air temperature and precipitation series for the European Climate Assessment. International Journal of Climatology 22: 1441-1453.

Lemin, G., Koch, G., Hurtgen, C. \& Pissart, A., 1987. Les transports en suspension de la Meuse, l'Ourthe et la Höegne. Bulletin de la Société Géographique de Liège 22-23: 39-61. 
Nash, J.E. \& Sutcliffe, J.V., 1970. River flow forecasting through conceptual models. A discussion of principles. Journal of Hydrology 10: 282-290.

Phillips, J.M., Webb, B.W., Walling, D.E. \& Leeks, G.J.L., 1999. Estimating the suspended sediment loads of rivers in the LOIS study area using infrequent samples. Hydrological Processes 13: 1035-1050.

Renard, K.G. \& Freimund, J.R., 1994. Using monthly precipitation data to estimate the R-factor in the revised USLE. Journal of Hydrology 157: 287-306.

Renard, K.G., Foster, G.R., Weesies, G.A., McCool, D.K. \& Yoder, D.C., 1997. Predicting soil erosion by water: A guide to conservation planning with the Revised Universal Soil Loss Equation (RUSLE). Agriculture Handbook vol. 703. U.S. Department of Agriculture (Washington D.C.): 384 pp.

Richards, K., Brasington, J. \& Hughes, F., 2002. Geomorphic dynamics of floodplains: ecological implications and a potential modelling strategy Freshwater Biology 47: 559-579.

Robertson, D.M. \& Roerish, E.D., 1999. Influence of various water quality sampling strategies on load estimates for small streams. Water Resources Research 35: 3747-3759.

Spring, W. \& Prost, E., 1883. Étude sur les eaux de la Meuse. Annales de la Société Géologique de la Belgique 11: 123-220.

Verstraeten, G. \& Poesen, J., 1999. The nature of small-scale flooding, muddy floods and retention pond sedimentation in central Belgium. Geomorphology 29: 275-292.

Verstraeten, G., Poesen, J., Demarée, G. \& Salles, C., 2006. Long-term (105 years) variability in rain erosivity as derived from 10 -min rainfall depth data for Ukkel (Brussels, Belgium): Implications for assessing soil erosion rates. Journal of Geophysical Research 111: D22109, doi:10.1029/2006JD007169.

Walling, D.E. \& Webb, B.W., 1982. Sediment availability and the prediction of storm-period sediment yields. In: Walling, D.E. (ed): Recent Developments in the Explanation and Prediction of Erosion and Sediment Yield. IAHS Publication number 137 (Wallingford, U.K.): 327-337.

Ward, P.J., Renssen, H., Aerts, J.C.J.H., Van Balen, R.T. \& Vandenberghe, J., 2008. Strong increases in flood frequency and discharge of the River Meuse over the late Holocene: impacts of long-term anthropogenic land use change and climate variability. Hydrology and Earth System Sciences 12: 159-175, www.hydrol-earth-syst-sci.net/12/159/2008/. 